\title{
The use of amniotic membrane in trabeculectomy for the treatment of primary open-angle glaucoma: a prospective study
}

This article was published in the following Dove Press journal:

Clinical Ophthalmology

I February 2012

Number of times this article has been viewed

\section{Panagiotis Stavrakas' \\ Gerasimos Georgopoulos' \\ Maria Milia' \\ Dimitris Papaconstantinou' \\ Maria $\mathrm{Bafa}^{2}$ \\ Efthymios Stavrakas ${ }^{2}$ \\ Mihalis Moschos'}

'Department of Ophthalmology, University of Athens Medical School, General Hospital of Athens (Geniko Kratiko Hospital), Athens, Greece; 2Department of Ophthalmology, Thriassio General Hospital, Athens, Greece
Correspondence: Panos Stavrakas Rimini I, Chaidari, I 2462, Greece Tel +306944276610 Fax +30 210 98। II 38 Email panos.stavrakas@yahoo.com
Background: To investigate the effectiveness of amniotic membrane transplantation (AMT) on improving the outcomes of trabeculectomy in primary open-angle glaucoma (POAG).

Methods: Fifty-nine eyes affected by primary open-angle glaucoma were enrolled in this prospective randomized study. Thirty-two eyes underwent amnion-shielded trabeculectomy (study group) and 27 eyes underwent trabeculectomy without any antimetabolites (control group). Success was defined as intraocular pressure (IOP) $<21 \mathrm{mmHg}$ without any medications at 24 months follow-up. The two groups were compared in terms of IOP, bleb morphology, bleb survival and risk of failure, glaucoma medications, and complications.

Results: There was no statistically significant difference in terms of postoperative IOP between the two groups and at 24 months median IOP was $15.5 \mathrm{mmHg}$ for the AMT group and $16 \mathrm{mmHg}$ for the control group. IOP postoperative reduction was $8 \mathrm{mmHg}$ for the AMT group versus $6 \mathrm{mmHg}$ for the non AMT group $(P=0.276)$. Two patients from the study group developed IOP $>21 \mathrm{mmHg}$ in contrast to seven patients from the classic trabeculectomy group. The study group had $61.0 \%$ less risk of developing IOP $>21 \mathrm{mmHg}(P=0.203)$. No major complications in the AMT group were observed. AMT blebs were diffuse with mild vascularization.

Conclusion: In patients with POAG, AMT showed favorable effects on bleb survival, however data failed to provide firm evidence that AMT could be used as a routine procedure in trabeculectomy.

Keywords: amniotic membrane, trabeculectomy, primary open-angle glaucoma, glaucoma filtering bleb

\section{Introduction}

Fibrosis and scarring occurring at the subconjunctival space is the main reason for failure of the most established glaucoma filtration surgery (GFS). ${ }^{1}$ The introduction and widespread use of antiproliferative agents affecting fibroblast proliferation ${ }^{2}$ and apoptosis $^{3}$ such as MM-C $\mathrm{C}^{4-7}$ and 5-FU ${ }^{8-10}$ have improved surgical outcomes; nevertheless, their well-known complications mean that safer alternatives for fibrosis control are still needed. ${ }^{11-14}$ There are several events in the healing process that can potentially be modified such as: inflammation; fibrin formation; growth factors and cytokines; cellular proliferation; differentiation, apoptosis and migration; wound contraction; and angiogenesis. ${ }^{15}$ Several older and newer agents have been tested in vitro and in vivo such as cyclosporine, tranilast $\left(N-\left[3^{\prime}, 4^{\prime}\right]\right.$-dimethoxycinnamol) anthranilic acid, ${ }^{15}$ suramin, ${ }^{16}$ ilomastat, ${ }^{17}$ Lerdelimumab Trabio CAT- $152^{18}$ and many others ${ }^{19}$ but none of them have yet entered clinical practice. 
Moreover, it is known that fibroblast proliferation and differentiation to myofibroblasts following surgical trauma at the site of trabeculectomy is promoted by tranforming growth factor $\beta$ (TGF $\beta$ ), and in particular the isoform TGF $\beta 2$ is one of the most potent scarring stimulators in the eye. ${ }^{20-22}$ Production of extracellular matrix by the activated fibroblasts leads to the formation of subconjunctival granular tissue ${ }^{23}$ followed by obstruction of the filtration site, ${ }^{24,25}$ hence targeting TGF- $\beta$ appears promising in reducing postoperative fibrosis.

Human amniotic membrane, known for its antifibrotic, anti-inflammatory and anti-angiogenic properties, suppresses transforming growth factor $\beta$ (TGF $\beta)^{26}$ and has been tested as an adjuvant in high-risk GFS, ${ }^{27,28}$ as a substrate for the repair of leaking glaucoma blebs, ${ }^{29}$ and for the management of tube exposure following tube shunt surgery. ${ }^{30}$ Although results from previous clinical and experimental studies of amniotic membrane transplantation in trabeculectomy have been promising, it remained unclear whether amniotic membrane could be used as a routine procedure for the prevention of fibrosis in GFS. For this purpose we carried out this prospective baseline study evaluating the effectiveness of AMT in trabeculectomy for the treatment of primary open-angle glaucoma (POAG). Characteristics of the amniotic membrane are discussed.

\section{Methods}

Sixty-one consecutive patients (70 eyes) with primary open glaucoma were assessed for eligibility to participate in the study. Five patients refused and six did not meet the inclusion criteria. Figure 1 shows the flow of the patients in the study. After informed consent was obtained, 59 eyes of 50 patients were randomized in two groups. The first group (study group) consisted of 27 eyes that received amniotic membrane transplantation at the trabeculectomy site and the second group (control group) consisted of 32 eyes that underwent standard trabeculectomy without any antimetabolites.

Inclusion criteria were the presence of POAG and at least one of the following: unsatisfactory target intraocular pressure (IOP) control with topical antiglaucoma treatment; optic nerve damage progression on two consecutive visual field tests and increase of cup-to-disk ratio in a period of 24 months; allergy to topical agents; or poor compliance. Exclusion criteria were: any other type of glaucoma; only-eye patients; past or present anterior segment pathology coexistence (apart from cataract); and previously failed glaucoma filtration surgery. The study design was according to the Declaration of Helsinki.

Human amniotic membranes were prepared as previously described. ${ }^{29,31}$ Human placenta was obtained under sterile condition shortly after cesarean section when Human Immunodeficiency Virus, Hepatitis B and C virus, syphilis, and Creutzfeldt-Jacob disease had been excluded with serological testing. Under a lamellar flow hood, the placenta was washed free of blood clots with sterile physiologic saline solution containing $50 \mathrm{mg} / \mathrm{mL}$ penicillin, $50 \mathrm{mg} / \mathrm{mL}$

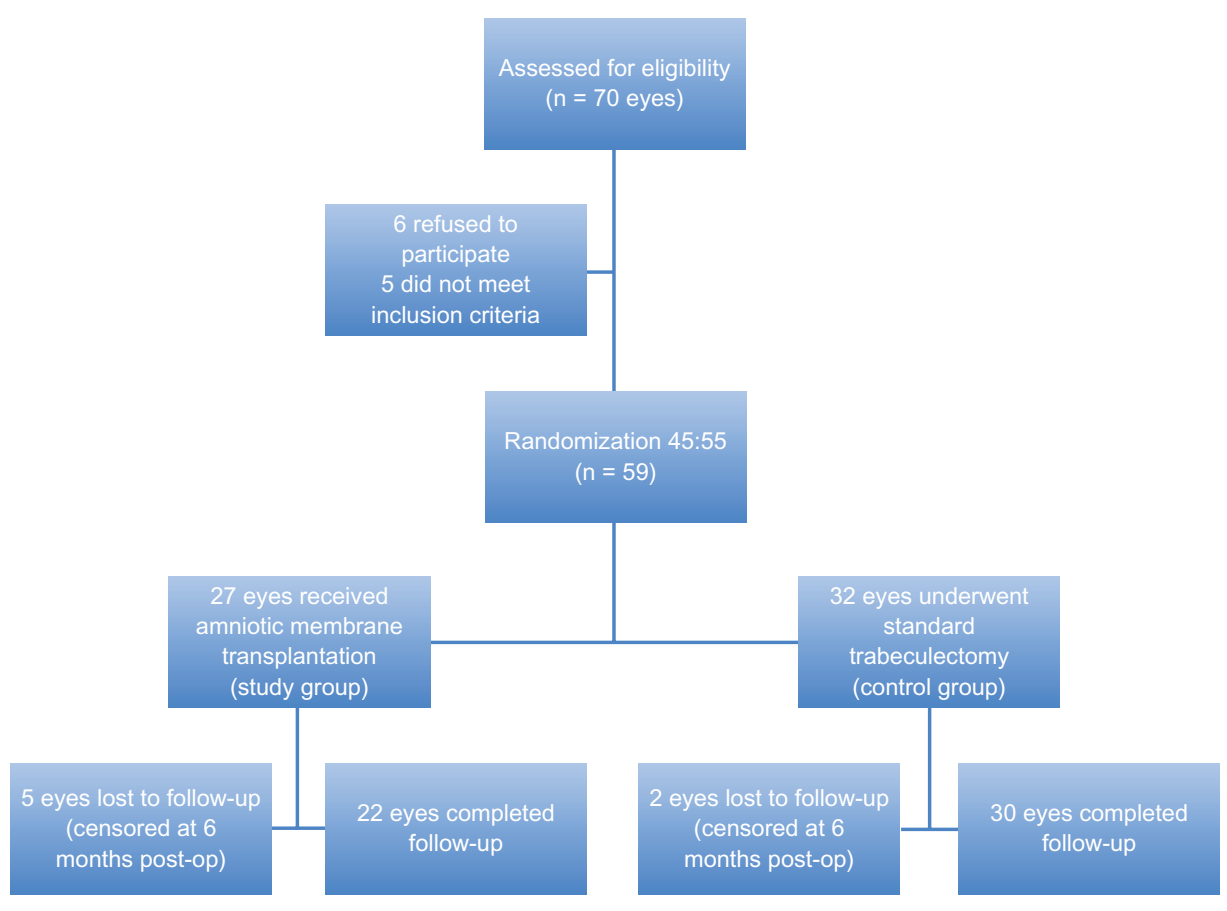

Figure I Flow chart showing the progression of patients in the study. 
streptomycin, $100 \mathrm{mg} / \mathrm{mL}$ neomycin, $2.5 \mathrm{mg} / \mathrm{mL}$ amphotericin, and subsequently the amnion was separated from the rest of the chorion with blunt dissection. The amniotic membrane was then placed on to nitrocellulose paper with the epithelial/basement membrane facing up, cut into rectangular pieces of $3 \times 3 \mathrm{~cm}$ and stored at $-80^{\circ} \mathrm{C}$ in sterile vials containing Dulbecco's Modified Eagle's solution and glycerol at a ratio of 1:1. The membranes for use were left to defrost for 10 minutes before surgery at operating theatre temperature and washed twice with balanced salt solution before transplantation.

Surgery was performed by two surgeons under inferior nasal fornix sub-Tenon's anesthesia consisting of lidocaine and marcaine at a ratio of 1:4. The surgical technique was as follows. A fornix-based superior conjunctival peritomy was performed followed by cautery and thorough cleaning of the scleral surface. A $3 \times 4 \mathrm{~mm}$ scleral flap was prepared and anterior chamber paracentesis was done followed by sclerectomy with Vannas scissors. Iridectomy was performed with iris scissors and the scleral flap secured with 28.0 nylon sutures. Once good filtration was assured, one rectangular piece of amniotic membrane measuring approximately $5 \times 5 \mathrm{~mm}$ was prepared and positioned over the scleral flap with the matrix side facing the scleral surface. No sutures were used to secure the membrane. Tenon's capsule and conjunctiva were positioned over the membrane and closed with interrupted 7.0 Vicryl sutures, taking extra care not to fold the amniotic membrane. The paracentesis tract was used to inject balanced salt solution into the anterior chamber to confirm aqueous flow in the newly formed bleb and check for leakage. Subconjunctival injection of betamethasone $1 \%$ and cefuroxime $125 \mathrm{mg}$ was administered in the inferior fornix.

The eye patch was removed the next morning and eyes were examined at 1 day, 1 week, 2 weeks, 1 month, 2 months, and every 6 months thereafter for a minimum of 2 years follow-up. Additional visits were scheduled at the discretion of the operating surgeon. The postoperative regime was identical for both groups and consisted of topical dexamethasone $1 \%$ and tobramycin 6 times daily for 1 month followed by a tapering schedule. Visual acuity, IOP, slit-lamp examination, and bleb characterization in terms of area, vascularity, and height based on the principles of the Moorfields Bleb Grading System was performed at each visit.

Results are given as median \pm inter quartile range (IQR) except where indicated. Statistical evaluation between categorical variables and type of surgery was performed using Fisher's Exact Test. A nonparametric Mann-Whitney test was used for comparison of continuous quantitative variables. The Wilcoxon matched-pairs signed ranks test was used for the statistical analysis of number of medications before and after surgery. Cox proportional hazards model and KaplanMeier analysis and curves were performed. A $P$ value less than 0.05 was considered statistically significant. Success was defined as IOP $<21 \mathrm{mmHg}$ without any medications at any stage of the follow-up. Primary outcome measures were IOP, and functionality and morphology of the bleb. The secondary outcome measure was the reduction of antiglaucoma medications. Eyes lost from follow-up have been included in the analysis until they stopped attending the scheduled postoperative visit and then censored from the study (right censoring). Intraoperative and postoperative complications were reported. All statistical analyses were performed with SPSS (v 16.0 for Windows; SPSS, Inc, Chicago, IL).

\section{Results}

A total of 59 eyes underwent statistical analysis, 27 of which received amniotic membrane transplantation (amniotic-study group, 45.7\%) and 32 underwent trabeculectomy without any antifibrotic agents (nonamniotic-control group, $54.3 \%$ ). Table 1 shows demographic and principal clinical characteristics. At 24 months follow-up, two patients from the study group and seven from the control group developed IOP $>21 \mathrm{mmHg}$ and had to start topical antiglaucoma treatment. There was no statistical difference in the number of medications between study and control group before surgery $(P=0.889)$ or after surgery $(P=0.302)$.

Figure 2 provides median intraocular pressures variation pre- and post-op for each group up to 24 months follow-up. There were no differences between the two groups (study group median IOP at 24 months was $15.5 \mathrm{mmHg}$ vs $16 \mathrm{mmHg}$ of the control group).

Table 2 shows the reduction of intraocular pressure for each group and the comparison between amniotic and nonamniotic eyes. At the end of the follow-up, IOP reduction in the study group was $8 \mathrm{mmHg}$ (median) and $6 \mathrm{mmHg}$ in the control group $(P=0.276)$. The $P$ value at each visit demonstrates that there was no statistically significant difference between the two groups.

The number of postoperative medications decreased significantly in both groups $(P<0.001)$ (Table 3$)$. Two patients in the amniotic group (9\%) and six patients in the nonamniotic group (20\%) needed topical antiglaucoma treatment.

The risk of developing IOP $\geq 21 \mathrm{mmHg}$ based on the type of surgery was calculated with the Cox Proportional Hazards Model. In 24 months follow-up, eyes that underwent 
Table I Demographics and principal clinical characteristics of amniotic and nonamniotic groups

\begin{tabular}{|c|c|c|c|}
\hline & $\begin{array}{l}\text { Nonamniotic } \\
\text { N (\%) }\end{array}$ & $\begin{array}{l}\text { Amniotic } \\
\mathbf{N}(\%)\end{array}$ & $P$-value \\
\hline Gender & & & 0.183 \\
\hline Female & $16(50.0)$ & $8(29.6)$ & \\
\hline Male & $16(50.0)$ & $19(70.4)$ & \\
\hline$I O P \geq 2$ I after operation & & & 0.16 \\
\hline No & $25(78.1)$ & $25(92.6)$ & \\
\hline \multirow[t]{2}{*}{ Yes } & $7(21.9)$ & $2(7.4)$ & \\
\hline & Median (IQR) & & \\
\hline \multirow[t]{2}{*}{ Age (years) } & $71.5(67.0,76.0)$ & $70.0(63.0,80.0)$ & 0.755 \\
\hline & Mean $(\min , \mathrm{ma}$ & & \\
\hline No of medicines before operation & $2.67(I, 4)$ & $2.64(I, 4)$ & 0.889 \\
\hline No of medicines after operation & $0.33(0,3)$ & $0.18(0,3)$ & 0.302 \\
\hline Reduction in no of medicines after operation & $2.33(0,4)$ & $2.45(0,4)$ & 0.766 \\
\hline
\end{tabular}

Abbreviations: IOP, intraocular pressure; IQR, median \pm inter quartile range.

amnion shielded trabeculectomy had $61.6 \%$ less risk of $\mathrm{IOP} \geq 21 \mathrm{mmHg}$ compared to eyes that underwent trabeculectomy without amniotic membrane transplantation. However the $P$ value was not statistically significant $(P=0.233)$. Figure 3 gives the estimated survival probabilities of IOP $\geq 21 \mathrm{mmHg}$ in the two groups.

With regards to bleb morphology, six eyes in the study group (22\%) had particularly elevated blebs at 2 weeks (Figure 4A) in contrast to only one (3\%) of the control group. All the amniotic blebs decreased in height and became diffuse with mild vascularization at 1 month post-op (Figure 4B and C). Only one eye from the study group had subconjunctival blood at 2 weeks, which resolved completely at 1 month. The same eye, at the end, developed a nonvascularized bleb with a cystic wall in the presence of a very good IOP control. At 6 months post-op, five of the 27 study eyes

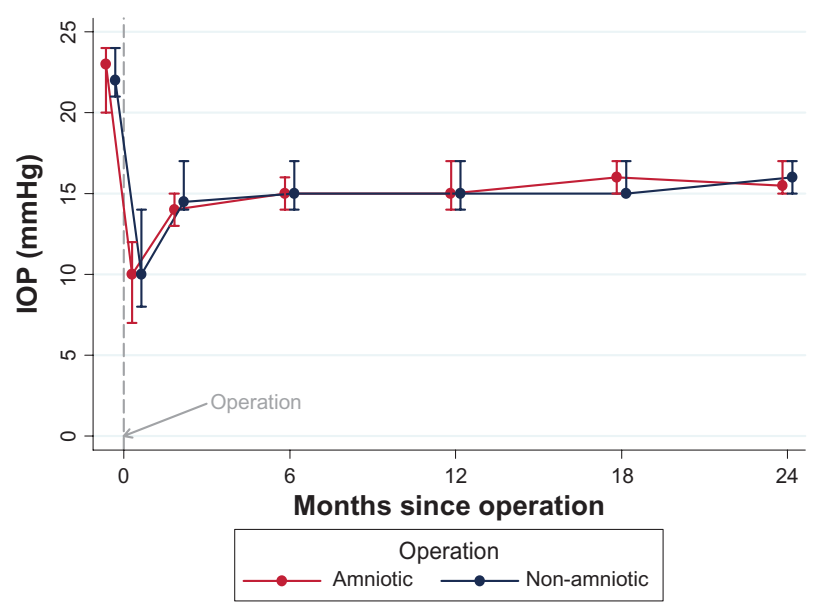

Figure 2 Plot of the intraocular pressure over time.

Notes: Bars indicate IQR. There was no statistical difference between the two groups at any time during the follow-up.

Abbreviations: IQR, median \pm inter quartile range; IOP, intraocular pressure.
(18\%) had a flat mildly vascularized bleb, 15 eyes (55.5\%) had a grade 2 bleb height with normal vascularization, and one bleb (3.7\%) was encysted (Figure 5). There were no thin avascular blebs. Of the control group, eight eyes (25\%) had a flat bleb, 20 eyes (62.5\%) had a grade 2 bleb with normal vascularization, and four eyes $(12.5 \%)$ had encysted blebs.

Postoperative interventions included laser suture lysis in one eye of the nonamniotic group that developed IOP $>21 \mathrm{mmHg}$ and subsequently the IOP normalized promptly. Three AMT eyes (11\%) and six control group eyes $(18.7 \%)$ presented with shallow anterior chambers the first day post-op, which deepened at the end of the first week without intervention.

In terms of complications there were no cases of endophthalmitis. One eye of the amniotic group had diffuse dot blot retinal hemorrhages at 1 week post-op probably related to intraoperative hypotony, which resolved spontaneously at 1 month and one eye presented with anterior chamber fibrin 48 hours following surgery due to poor compliance because the patient did not instill steroids at all. The fibrin resolved promptly following subconjunctival injection of steroids. There were three eyes from the control group that developed limited choroidal detachment not threatening the macula or affecting vision, which fully resolved by the end of the first 4 weeks. There were no leaking blebs and no eyes needed urgent reintervention.

Visual acuity (VA) remained essentially unchanged for the first 6 months post-op and there was no difference between the two groups in terms of cataract progression (Table 4). However, from the sixth month until the end of the follow-up some of the patients had to be listed for cataract surgery, therefore VA was excluded from further statistical analysis. 
Table 2 Reduction of intraocular pressure pre- and post-op for each group up to 24 months follow-up and comparison between the two groups

\begin{tabular}{llll}
\hline & $\begin{array}{l}\text { Nonamniotic } \\
\text { median (IQR) }\end{array}$ & $\begin{array}{l}\text { Amniotic } \\
\text { median (IQR) }\end{array}$ & P-value \\
\hline I day after operation & $-12.0(-16.0,-9.5)$ & $-13.0(-16.0,-11.0)$ & 0.609 \\
2 months after operation & $-7.0(-10.0,-6.0)$ & $-8.0(-10.0,-6.0)$ & 0.603 \\
6 months after operation & $-7.0(-10.0,-4.0)$ & $-7.5(-10.0,-6.0)$ & 0.758 \\
I2 months after operation & $-7.0(-9.0,-5.0)$ & $-7.5(-9.0,-5.5)$ & 0.668 \\
18 months after operation & $-7.0(-9.0,-5.0)$ & $-8.0(-10.0,-6.0)$ & 0.524 \\
24 months after operation & $-6.0(-8.5,-4.5)$ & $-8.0(-9.0,-6.0)$ & 0.276 \\
\hline
\end{tabular}

Note: *Statistically significant at 0.0083 level (after Bonferroni correction for multiple comparisons).

Abbreviation: IQR, median \pm inter quartile range.

\section{Discussion}

Healing response after glaucoma filtration surgery is the main determinant of surgical failure, therefore wound healing modulation appears to be the key element in order to improve trabeculectomy outcomes.

The amniotic membrane is the innermost layer of the fetal membranes and has multiple properties ${ }^{26}$ that might be beneficial in the process of wound healing modulation in glaucoma filtration surgery such as angiogenesis suppression, good epithelization, no host rejection, high hydraulic conductivity, low healing response, ${ }^{1}$ and more importantly it downregulates the TGF- $\beta 2 .{ }^{32}$ It was Fujishima et al who first suggested the use of AMT in GFS in $1998^{28}$ followed by Barton et $\mathrm{al}^{1}$ who demonstrated improved trabeculectomy survival rate in experimental glaucoma surgery and launched the idea of AM transplantation in trabeculectomy. Droslum et al used a double sheet of amniotic membrane impregnated in MM-C in nine patients with refractory glaucoma with encouraging results but no control group, ${ }^{27}$ similarly to Sheha et al who found significant advantage in using a single layer of AM and MM-C under the scleral flap

Table 3 Number of topical antiglaucoma medications before and after surgery for each group

\begin{tabular}{lll}
\hline No of medicines & $\begin{array}{l}\text { Before operation } \\
\mathbf{N}(\%)\end{array}$ & $\begin{array}{l}\text { After operation } \\
\mathbf{N}(\%)\end{array}$ \\
\hline Nonamniotic & & \\
0 & $0(0)$ & $26(8 I .2)$ \\
1 & $1(3.1)$ & $3(9.3)$ \\
2 & $12(37.5)$ & $2(6.2)$ \\
3 & $15(46.8)$ & $1(3.1)$ \\
4 & $4(12.5)$ & $0(0)$ \\
Amniotic & & \\
0 & $0(0)$ & $25(92.5)$ \\
I & $I(3.7)$ & $1(3.7)$ \\
2 & $9(33.3)$ & $0(0)$ \\
3 & $14(51.8)$ & $I(3.7)$ \\
4 & $3(11.1)$ & $0(0)$ \\
\hline
\end{tabular}

Note: $P$-value (Wilcoxon matched-pairs signed-ranks test): $<0.00$ I. compared to only MM-C in a prospective study of 37 eyes with refractory glaucoma. ${ }^{33}$ Zheng found no difference in trabeculectomy with neither AM or MM-C in a prospective study of 48 eyes $^{34}$ whereas Eliezer used a folded membrane over the sclera and did not notice a statistically significant difference in terms of IOP between classic and amnion shielded trabeculectomy at 12 months follow-up in 32 eyes with POAG ${ }^{35}$ In further experiments amniotic membrane was shown to be less effective than $\mathrm{MMC}^{36}$ and octreotide ${ }^{37}$ in reducing fibroblast proliferation in GFS but still with a significant antifibrotic effect.

This was a prospective randomized study assessing the efficacy of amniotic membrane transplantation in trabeculectomy with, to the best of our knowledge, the longest follow-up period (24 months) and the largest number of participating eyes (59 eyes). In order to assess a therapeutic intervention it is essential to compare efficacy and complications against a standard procedure. Trabeculectomy, almost 40 years since its introduction, ${ }^{38}$ remains the gold standard in GFS for POAG, and we chose patients with POAG because it is the most common type of glaucoma. We set IOP $<21 \mathrm{mmHg}$ as

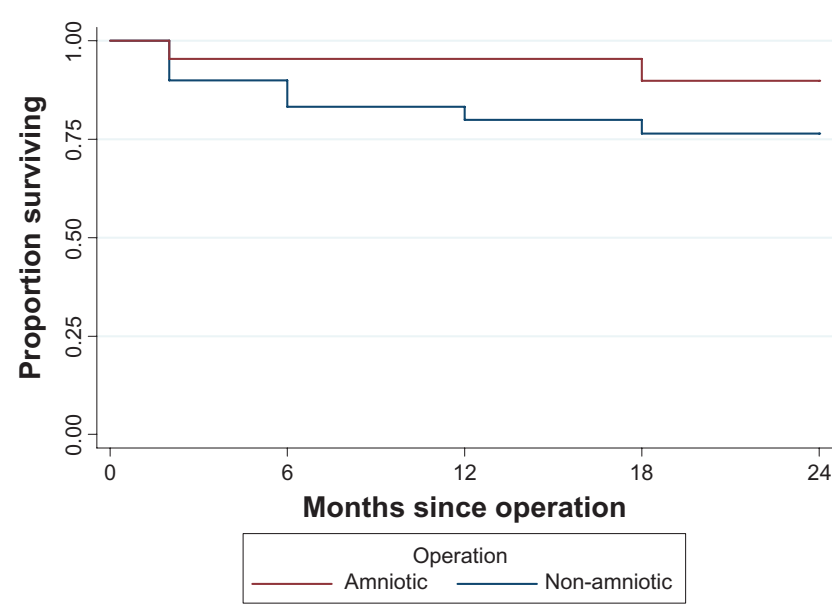

Figure 3 Kaplan-Meier filtration surgery survival curve. 

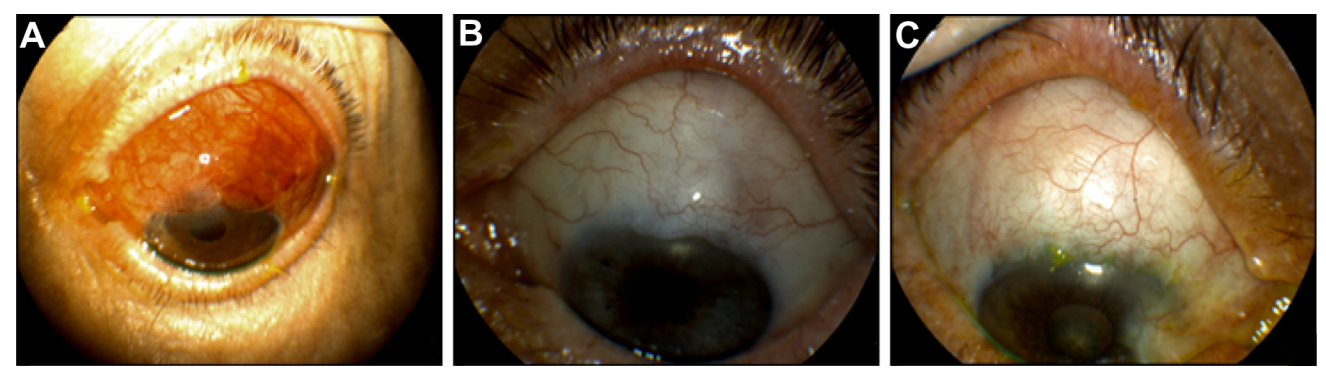

Figure 4 Appearance of elevated amnion shielded trabeculectomy bleb at I week post-op (A). Amniotic group blebs at I month post-op. The blebs are diffuse, with mild vascularization (B and $\mathbf{C}$ ).

the endpoint in order to be comparable with the majority of the published surgical trials of trabeculectomy survival and did not use any antimetabolites because the aim was a baseline study of the amniotic membrane in GFS. Demographics were similar in both study and control groups and the preoperative intraocular pressures and number of medications did not differ significantly. We positioned the amniotic layer over the scleral flap based on the assumption that fibrosis responsible for bleb failure is primarily formed at the subconjunctival space. This is the first study where the amnion was not sutured, resulting in shorter operative time and potentially fewer intraoperative complications. The surgical technique followed by the two surgeons was the same in order to reduce intra-observer bias.

Results show that postoperative IOP levels were arithmetically lower in the amnion group but never reached statistically significant levels throughout the 24 months of follow-up. Reduction of IOP was greater in the amniotic group and at 24 months the difference between study and control group reached $2 \mathrm{mmHg}$, however the $P$ value was again not significant. Of better value to the comparison

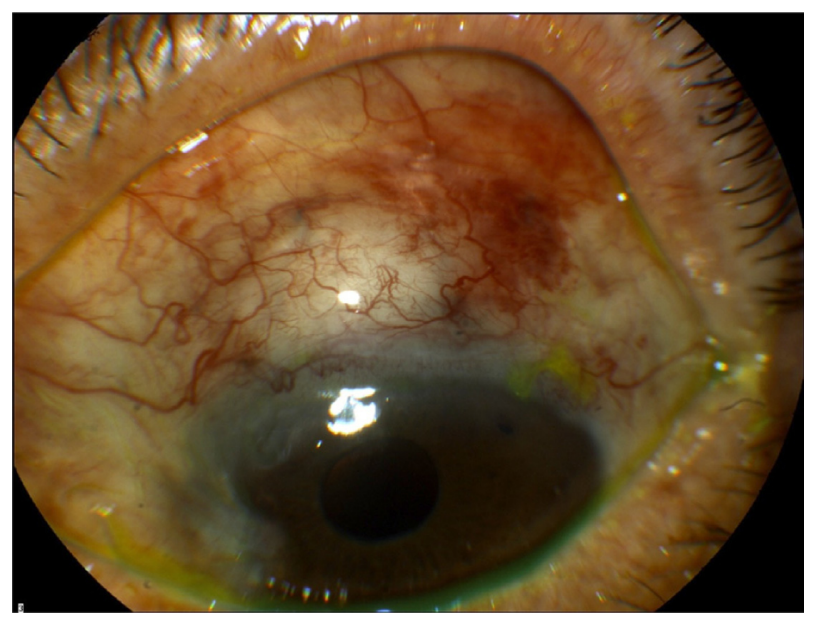

Figure 5 Cystic bleb of the amniotic group at 2 weeks post-op. The bleb remained dysfunctional throughout the follow-up. between the two groups seems to be the survival curve and the risk of developing IOP $\geq 21 \mathrm{mmHg}$. In fact the AMT filtration procedure showed longer survival in terms of IOP reduction (Figure 3) and 61\% less risk of failure compared to the standard procedure. Unfortunately the $P$ value failed to reach statistical significance and, based on the risk value, we believe this is probably due to the relatively small size of the study population rather than ineffectiveness of the AMT.

Bleb morphology showed more diffuse and mildly vascularized blebs in the AMT group, compared to flatter blebs in the control group. This could be associated with a better bleb function with a more diffuse area of drainage and less risk of cystic, thin-walled blebs that we observe when treating with antimetabolites. The aforementioned is supported by the anti-scarring properties of the AM. No major intra- or postoperative complications were noted and no re-operations for leakage were needed, thus AMT proved safe and easy to perform. Patients did not complain of dysesthetic blebs since the initially elevated AMT blebs normalized in height 4 weeks following surgery, in agreement with previous observations in rabbits that $\mathrm{AM}$ dissolves in approximately 1 month. ${ }^{39}$

The unequal number of study and control eyes is an obvious weakness of this study and this is because in the first year of the study, five patients from the AMT group and two from the control group were lost to follow-up and therefore included in the first 6 months data analysis only. They were excluded thereafter, using right censoring in order to avoid major bias in the long-term results since those were, according to our opinion, of major importance. Furthermore we used one single layer of amniotic membrane in contrast to previous reports of folded or double layer of AM, because we did not have strong evidence to support a synergistic effect of more layers of AM.

Like any other biological substrate transplantation, amniotic membrane transplantation has a potential danger of spreading viruses and bacteria. The risk of infections is 
Table 4 Visual acuity (Snellen lines) pre-op and at 6 months follow-up. There were no statistical differences between the two groups

\begin{tabular}{llll}
\hline & $\begin{array}{l}\text { Nonamniotic } \\
\text { median (IQR) }\end{array}$ & $\begin{array}{l}\text { Amniotic } \\
\text { median (IQR) }\end{array}$ & P value \\
\hline Pre-op VA & $0.4(0.1,0.5)$ & $0.5(0.2,0.6)$ & 0.36 \\
6 months post-op VA & $0.3(0.1,0.5)$ & $0.3(0.2,0.5)$ & 0.489 \\
VA (6 months) post-op-pre-op & $-0.1(-0.1,0.0)$ & $-0.1(-0.1,0.0)$ & 0.377 \\
\hline
\end{tabular}

Abbreviations: IQR, median \pm inter quartile range; VA, visual acuity.

minimized if adequate donor screening and serological testing is performed and it is imperative to respect the 6 months window period and retest the donor before the amnion is used. Moreover, it is recommended that amnion for use in ocular surgery should be obtained from elective cesarean deliveries. $^{40}$

With this prospective randomized study we tried to investigate the usefulness of AMT in trabeculectomies for the treatment of primary open glaucoma. In conclusion, the aforementioned outcomes were suggestive of a favorable effect of the AM on wound healing and bleb survival; nevertheless our data do not provide firm evidence that AMT should be used as a routine procedure in the surgical treatment of POAG.

\section{Acknowledgment}

Part of this study has been presented as a poster at the ARVO 2007 annual meeting, Fort Lauderdale, FL.

\section{Disclosure}

None of the authors has any financial interest in any of the materials or the methods mentioned in the study.

\section{References}

1. Barton K, Budenz DL, Khaw PT, Tseng SC. Glaucoma filtration surgery using amniotic membrane transplantation. Invest Ophthalmol Vis Sci. 2001;42(8):1762-1768.

2. Khaw PT, Doyle JW, Sherwood MB, Grierson I, Schultz G, McGorray S. Prolonged localized tissue effects from 5-minute exposures to fluorouracil and mitomycin C. Arch Ophthalmol. 1993;111(2):263-267.

3. Crowston JG, Akbar AN, Constable PH, Occleston NL, Daniels JT, Khaw PT. Antimetabolite induced apoptosis in Tenon's capsule fibroblasts. Invest Ophthalmol Vis Sci. 1998;39(2):449-454.

4. Chen CW. Enhanced intraocular pressure controlling effectiveness of trabeculectomy by local application of mitomycin-C. Trans Asia Pacific Acad Ophthalmol. 1983;9:172-177.

5. Chen CW, Huang HT, Bair JS, Lee CC. Trabeculectomy with simultaneous topical application of mitomycin $\mathrm{C}$ in refractory glaucoma. $\mathrm{J} \mathrm{Ocul}$ Pharmacol. 1990;6(3):175-182.

6. Mermoud A, Salmon JF, Murray AD. Trabeculectomy with mitomycin C for refractomy glaucoma in blacks. Am J Ophthlamol. 1993; 116(1):72-78.

7. Kitazawa Y, Kawase K, Matsushita H, Minobe M. Trabeculectomy with mitomycin: a comparative study with fluorouracil. Arch Ophthalmol. 1991;109(12):1693-1698.
8. The fluorouracil filtering study group. Five year follow-up of the fluorouracil filtering surgery study group. Am J Ophthalmol. 1996; 121(4):349-366.

9. Rockwood EJ, Parrish RK, Heuer DK, et al. Glaucoma filtering surgery with 5-fluorouracil. Ophthalmology. 1987;94(9):1071-1078.

10. Smith MF, Sherwood MB, Doyle JW, Khaw PT. Results of intraoperative 5-fluorouracil supplementation on trabeculectomy for open angle glaucoma. Am J Ophthalmol. 1992;114(6):737-741.

11. Zacharia PT, Deppermann SR, Schuman JS. Ocular hypotony after trabeculectomy with mytomycin C. Am J Ophthalmol. 1993;116(3): 314-326.

12. Parrish RK II, Minckler D. Late endophthalmitis-filtering surgery time bomb? Ophthalmology. 1996;103(8):1167-1168.

13. Franks WA, Hitchings RA. Complications of 5 Fluorouracil after trabeculectomy. Eye. 1991;5(Part 4):385-389.

14. Higginbotham EJ, Stevens RK, Musch DC, et al. Bleb-related endophthalmitis after trabeculectomy with mitomycin C. Ophthalmology. 1996;103(4):650-656.

15. Khaw PT, Chang L, Wong TT, Mead A, Daniels JT, Cordeiro MF. Modulation of wound healing after glaucoma surgery. Curr Opin Ophthalmol. 2001;12(2):143-148.

16. Mietz H, Krieglstein GK. Suramin to enhance glaucoma filtering procedures: a clinical comparison with mitomycin. Ophthalmic Surg Lasers. 2001;32(5):358-369.

17. Wong TL, Mead LA, Khaw PT. Matrix metalloproteinase inhibition modulates postoperative scarring after experimental glaucoma filtration surgery. Invest Ophthalmol Vis Sci. 2003;44(3): 1097-1103.

18. Siriwardena D, Khaw PT, King AJ. Human antitransforming growth factor $\beta_{2}$ monoclonal antibody: a new modulator of wound healing in trabeculectomy - a randomized placebo controlled clinical study. Ophthalmology. 2002;109(3):427-431.

19. Georgoulas S, Dahlmann-Noor A, Brocchini S, Khaw PT. Modulation of wound healing during and after glaucoma surgery. Prog Brain Res. 2008;173:237-254.

20. Khaw PT, Occleston NL, Schultz GS, Grierson I, Sherwood MB, Larkin G. Activation and suppression of fibroblast activity. Eye. 1994;8(Pt 2):188-195.

21. Cordeiro MF, Bhattacharya SS, Shultz GS, Khaw PT. TGF beta 1, beta 2 , and beta 3 in vitro: biphasic effects on Tenon's fibroblast contraction, proliferation and migration. Invest Ophthalmol Vis Sci. 2000; 41(3):756-763.

22. Cordeiro MF, Siriwardena D, Chang L, Khaw PT. Wound healing modulation after glaucoma surgery. Curr Opin Ophthalmol. 2000; 11(2):121-126.

23. Jampel HD, McGuigan LJB, Dunkenlberger GR, L'Hernault NL, Quigley HA. Cellular proliferation after experimental glaucoma surgery. Arch Ophthalmol. 1988;106(1):89-94.

24. Miller MH, Grierson I, Unger WI, Hitchings RA. Wound healing in an animal model of glaucoma fistulizing surgery in the rabbit. Ophthalmic Surg. 1989;20(5):350-357.

25. Skuta GL, Parrish RK 2nd. Wound healing in glaucoma filtering surgery. Surv Ophthalmol. 1987;32(3):149-170.

26. Dua HS, Gomes JA, King AJ, Maharajan VS. The amniotic membrane in ophthalmology. Surv Ophthalmol. 2004;49(1):51-77. 
27. Droslum L, Willoch C, Nicolaissen B. Use of amniotic membrane as an adjuvant in refractory glaucoma. Acta Ophthalmol. 2006; 84(6):786-789.

28. Fujishima H, Shimazaki J, Shinozaki N, Tsubota K. Trabeculectomy with the use of amniotic membrane for uncontrollable glaucoma. Ophthalmic Surg Lasers. 1998;29(5):428-431.

29. Budenz DL, Barton K, Tseng SGC. Amniotic membrane transplantation for repair of leaking glaucoma filtering blebs. Am J Ophthalmol. 2000;130(5):580-588.

30. Ainworth G, Rotchford A, Dua HS, King AJ. A novel use of amniotic membrane in the management of tube exposure following glaucoma tube shunt surgery. Br J Ophthlamol. 2006;90(4):417-419.

31. Tsubota K, Satake Y, Ohyama M, et al. Surgical reconstruction of the ocular surface in advanced cicatricial pemphigoid and Stevens-Johnson Syndrome. Am J Ophthalmol. 1996;122(1):38-52.

32. Tseng SC, Li DQ, Ma X. Suppression of transforming growth factor-beta isoforms, TGF-beta receptor type II, and myofibroblast differentiation in cultured human corneal and limbal fibroblasts by amniotic membrane matrix. J Cell Physiol. 1999;179(3):325-335.

33. Sheha H, Keirkhah A, Taha H. Amniotic membrane transplantation in trabeculectomy with mitomycin $\mathrm{C}$ for refractory glaucoma. J Glaucoma. 2008;17(4):303-307.
34. Zheng K, Huang Z, Zou H, Li H, Huang Y, Xie M. The comparison study of glaucoma trabeculectomy applying amniotic membrane or mitomycin C. Yan Ke Xue Bao. 2005;21(2):84-87. Chinese.

35. Eliezer RN, Kasahara N, Caixeta-Umbelino C, Pinheiro RK, Mandia C Jr, Malta RF. Use of amniotic membrane in trabeculectomy for the treatment of glaucoma: a pilot study. Arq Bras Oftalmol. 2006; 69(3):309-312.

36. Demir T, Turgut B, Akyol N, Ozercan I, Ula F, Celiker U. Effects of amniotic membrane transplantation and mitomycin $\mathrm{C}$ on wound healing in experimental glaucoma surgery. Ophthalmologica. 2002; 216(6):438-442.

37. Demir T, Turgut B, Celiker U, Ozercan I, Ulas F, Akyol N. Effects of octreotide acetate and a, miotic membrane on wound healing in experimental glaucoma surgery. Doc Ophthalmol. 2003;107(2):87-92.

38. Cairns JE. Trabeculectomy: a preliminary report of a new method. Am J Ophthalmol. 1968;66(4):673-679.

39. Wang L, Liu X, Zhang P, Lin J. An experimental trial of glaucoma filtering surgery with amniotic membrane. Yan Ke Xue Bao. 2005; 21(2):126-131. Chinese.

40. Adds PJ, Hunt C, Hartley S. Bacterial contamination of amniotic membrane. Br J Ophthalmol. 2001;85(2):228-230.
Clinical Ophthalmology

\section{Publish your work in this journal}

Clinical Ophthalmology is an international, peer-reviewed journal covering all subspecialties within ophthalmology. Key topics include: Optometry; Visual science; Pharmacology and drug therapy in eye diseases; Basic Sciences; Primary and Secondary eye care; Patient Safety and Quality of Care Improvements. This journal is indexed on

\section{Dovepress}

PubMed Central and CAS, and is the official journal of The Society of Clinical Ophthalmology (SCO). The manuscript management system is completely online and includes a very quick and fair peer-review system, which is all easy to use. Visit http://www.dovepress.com/ testimonials.php to read real quotes from published authors. 